\title{
Direitos Fundamentais Sociais: Quais são na verdade estes direitos?
}

\author{
Thiago Roberto Vilela Garcia*
}

\begin{abstract}
*Bacharel em Direito, Pós-Graduado em Direito Público pela Unaerp. Oficial de Justiça Avaliador (TJMG). E-mail: thiagorvgarcia@yahoo.com.br
\end{abstract}

Recebido em: 14/04/2015 - Aprovado em: 20/08/2015 - Disponibilizado em: 30/10/2015

\begin{abstract}
Resumo: A Constituição Brasileira abriga direitos fundamentais dos mais variados conteúdos, porém, todos têm em comum a fundamentalidade (formal e material). Entre estes direitos da pessoa humana positivados no ordenamento jurídico pátrio, estão os diretos de defesa que impõem uma abstenção do Estado e os de prestação que definem um fazer. Nesse contexto há bastante confusão quanto à identificação dos direitos fundamentais sociais. É falsa a ideia que aponta serem os direitos fundamentais de prestação ou prestacionais sinônimos de direitos sociais. É que existem direitos sociais tanto prestacionais quanto de defesa, sendo ainda que a categoria dos prestacionais não se limita a uma prestação material, alcançando as prestações jurídicas à proteção e à participação na organização e procedimento. Destarte, a identificação de um direito fundamental como social envolve mais do que análise de sua função (em que se baseiam as classificações), na verdade adquire seu contorno da sua acepção, da sua natureza, sendo entendidos como os direitos que inserem o ser humano no seio da vida comunitária, objetivando sua colocação definitiva (igualdade material) no âmbito social, político, cultural. Palavras-chave: Constituição Federal. Direito Fundamental. Direito Social
\end{abstract}

\begin{abstract}
The Brazilian Constitution holds fundamental rights of the most varied content, but all have in common the fundamentality (formal and equipment). Among these rights of the individual, positivized the Brazilian legal system, are the direct defense of imposing an abstention of the state and the provision defining a do. In this context there is a lot of confusion as to the identification of fundamental social rights. It is false the idea that points are fundamental rights to provide or prestacionais synonymous with social rights. It is that there are social rights both prestacionais as defense, still being that the category of prestacionais is not limited to a substantive provision, reaching legal services to the protection and participation in the organization and procedure. Thus, the identification of a fundamental right as social involves more than analysis of its function (they are based on the ratings) actually gets its contour to its meaning, its nature, being understood as the rights inserting the human within the community life, aiming its final placement (material equality) in the social, political, cultural.
\end{abstract}

Keywords: The Federal Constitution. Fundamental Right. Social Right.

\section{Introdução}

Os direitos sociais foram incluídos no rol de Direitos Fundamentais na Constituição Brasileira de 1988, o que significou um grande avanço para o que chamamos de constitucionalismo, ou seja, uma
Constituição repleta de valores que são considerados normas jurídicas.

No Brasil nenhuma outra Constituição havia conferido tamanha envergadura aos direitos sociais a ponto, inclusive, de inseri-los num capítulo próprio, sem falar em outros direitos de mesmo conteúdo, esparsos por nossa Carta Constitucional. 
Como nos ensina Miguel Reale (apud Nader, 2006) o Direito é fato, valor e norma, e o constituinte de 1988 ao reconhecer os direitos fundamentais da pessoa humana teve o condão de corrigir séculos e mais séculos de negação da própria natureza do homem, positivando valores inestimáveis, oriundos (a grande maioria) da dignidade da pessoa humana e ao dar-lhe força normativa, buscou, sobretudo, sua proteção.

Entre esses direitos estão os chamados pela própria Constituição de sociais, os quais têm por objetivo inserir a pessoa no seio comunitário em igualdade de condições com as demais, seja no âmbito social, político ou cultural.

\section{Conceito de Direitos Fundamentais}

$$
\text { Primeiramente, para }
$$
entendermos o que são direitos sociais devemos entender primeiro o gênero: direitos fundamentais. $\mathrm{O}$ melhor conceito de direito fundamental é o que revela sê-lo uma norma impregnada de "fundamentalidade" (Sarlet 2001). Mas o que vem a ser fundamentalidade? É uma característica intrínseca aos direitos fundamentais e pode ser vista sob o aspecto material, como o reconhecimento e proteção de certos valores, bens jurídicos e reivindicações essenciais aos seres humanos e também sob o ponto vista formal, como direitos inscritos na norma suprema do ordenamento jurídico, sendo inclusive, consideradas cláusulas pétreas.

Tal conceito é extraído dos ensinamentos de Ingo Sarlet (2001), um dos maiores expoentes do tema, que com suas palavras assim se refere aos direitos fundamentais:

(...) posições jurídicas concernentes às pessoas, que, do ponto de vista do direito constitucional positivo, foram, por seu conteúdo e importância fundamentalidade material), integradas ao texto da Constituição e, portanto, retiradas da esfera de disponibilidade dos poderes constituídos (fundamentalidad e formal) bem como as que, pelo seu objeto e significado, possam lhes ser equiparados, tendo, ou não, assento na 


Constituição
formal (aqui
consideramos a
abertura material
consagrada no art.
$5^{\circ}, \S 2^{\circ}$, da CF,
que prevê o
reconhecimento
de direitos
fundamentais
implícitos,
decorrentes do
regime e dos
princípios da
Constituição, bem
como direitos
expressamente
positivados em
tratados
internacionais).

Como se vê o que distingue os direitos fundamentais dos demais direitos é, sobretudo, o fato de estarem radicados numa Constituição formal quanto ao conteúdo, porque são alçados à norma suprema do ordenamento jurídico, inclusive considerados cláusulas pétreas (imodificáveis pelo poder constituinte derivado) e também sob o aspecto material serem nada menos que expressões da dignidade da pessoa humana (ao menos a maioria), ou seja, núcleo essencial da democracia (é que sem o reconhecimento e a eficácia de direitos fundamentais não há democracia (democracia material)).
Classificação dos Direitos Fundamentais

Antes de entrarmos na categoria dos direitos fundamentais sociais, é fundamental relembrarmos uma tradicional classificação que tem por foco a função exercida por esses direitos. São: direitos fundamentais como direitos de defesa e como direitos a prestações (de natureza fática e jurídica). Este segundo grupo - dos direitos a prestações - dividir-se-ia igualmente em dois subgrupos, quais sejam os direitos a prestações em sentido amplo (englobando, por sua vez, os direitos à proteção e os direitos à participação na organização e procedimento) e o dos direitos a prestações em sentido estrito.

Os direitos de defesa são de proteção do indivíduo contra ingerências do Estado em sua liberdade pessoal e propriedade. Acima de tudo, os direitos fundamentais - na condição de direitos de defesa - objetivam a limitação do poder estatal, assegurando ao indivíduo uma esfera de liberdade e lhe outorgando um direito subjetivo que lhe permita evitar interferências indevidas no âmbito de proteção do direito fundamental ou mesmo a 
eliminação de agressões que esteja sofrendo em sua esfera de autonomia pessoal. Segundo o magistério de Gomes Canotilho (apud Ingo Sarlet 2001): fundamentais cumprem a função de direitos de defesa dos cidadãos sob uma dupla perspectiva: (1) constituem, num plano jurídico-objetivo, normas de competência negativa para os poderes públicos, proibindo fundamentalment e as ingerências destes na esfera individual; (2) implicam, num plano jurídicosubjetivo, o poder de exercer positivamente direitos fundamentais (liberdade positiva) e de exigir omissões dos poderes públicos, de forma a evitar agressões lesivas por parte dos mesmos.

Os direitos fundamentais na sua função defensiva caracterizam-se, portanto, essencialmente, como direitos negativos, dirigidos precipuamente a uma conduta omissiva por parte do destinatário (Estado ou particulares - na medida em que se pode admitir uma eficácia horizontal dos direitos fundamentais). Abrangem, além dos assim denominados direitos de liberdade, a igualdade perante a lei, o direito à vida e o direito de propriedade, os quais integram $o$ que se convencionou chamar de primeira geração dos direitos fundamentais. $\mathrm{O}$ que deve ser muito bem realçado é que fazem parte deste grupo todos os direitos fundamentais que objetivam, em primeira linha, a proteção de certas posições jurídicas contra ingerências indevidas, de tal sorte que, segundo Ingo Sarlet (2001), “em princípio, se cuida de garantir a livre manifestação da personalidade (em todos os seus aspectos), assegurando, além disso, uma esfera de autodeterminação (autonomia) do indivíduo". Infere-se então, que a seara dos direitos de defesa ("status negativus") é muito ampla, englobando também as garantias fundamentais (direitos-garantia), os direitos políticos, a proteção da intimidade e vida privada, e até mesmo parte dos direitos sociais.

Por sua vez, decorrentes do princípio advindo do Estado Social de 
Direito de que o Estado deve, além da não intervenção na esfera de liberdade pessoal dos indivíduos, assegurada pelos direitos de defesa, colocar à disposição das pessoas os meios materiais e implementar as condições fáticas que possibilitem o efetivo exercício das liberdades fundamentais, surgem os direitos fundamentais a prestações.

Os prestacionais objetivam a garantia não apenas da liberdadeautonomia (liberdade perante o Estado), mas também da liberdade por intermédio do Estado, partindo da premissa de que o indivíduo, no que concerne à conquista e manutenção de sua liberdade, depende em muito de uma postura ativa dos Poderes Públicos. Assim, enquanto os direitos de defesa se dirigem, em princípio, a uma posição de respeito e abstenção por parte dos Poderes Públicos, os direitos a prestações, que, de modo geral, e ressalvados os avanços que podem ser registrados ao longo do tempo, podem ser reconduzidos ao "status positivus", implicam postura ativa do Estado, no sentido de que este se encontra obrigado a colocar à disposição dos indivíduos prestações de natureza jurídica e material (fática).

Tais direitos fundamentais, enquadram-se no âmbito dos assim denominados direitos de segunda geração (ou dimensão), correspondendo à evolução do Estado de Direito para o Estado Democrático e Social de Direito consagrando-se apenas neste século, principalmente após a Segunda Guerra Mundial.

$\mathrm{Na}$ Constituição Brasileira, os direitos a prestações encontram-se positivados, de modo especial no capítulo dos direitos sociais. Contudo, verifica-se que, mesmo em outras partes do texto constitucional (inclusive fora do catálogo dos direitos fundamentais), se encontra uma variada gama de direitos a prestações. Basta, neste contexto, uma breve referência aos exemplos do art. $17, \S 3^{\circ}$, da $\mathrm{CF}$ (direito dos partidos políticos a recursos do fundo partidário), bem como do art. $5^{\circ}$, incs. XXXV e LXXIV (acesso à Justiça e assistência jurídica integral e gratuita), para que possamos perceber nitidamente que, até mesmo entre os direitos políticos e direitos individuais (terminologia da Constituição), encontramos direitos fundamentais que 
exercem precipuamente uma função

prestacional.

$$
\text { Para um melhor }
$$

entendimento vale ressaltar seguindo a

habilidade tradicional de Ingo Sarlet (2001), que longe de serem homogêneos, os direitos prestacionais podem ser divididos em dois grupos:

$\begin{array}{lr}\text { direitos } & \text { a } \\ \text { prestações } & \text { em } \\ \text { direitos } & \text { a } \\ \text { prestações } & \\ \text { materiais } & \text { ou } \\ \text { fáticas e direitos a } \\ \text { prestações } & \\ \text { normativas } & \text { ou } \\ \text { jurídicas } & \text { Neste }\end{array}$
jurídicas. Neste contexto, se deve atentar para o fato de que os direitos a prestações não se restringem aos chamados direitos sociais, entendidos como direitos a prestações fáticas, englobando também os direitos à proteção e direitos à participação na organização e procedimento.

Distingue-se, portanto, entre os direitos a prestações em sentido amplo (direitos à proteção e participação na organização e procedimento), que, de certa forma, podem ser reconduzidos primordialmente ao Estado de Direito na condição de garante da liberdade e igualdade do "status negativus", e os direitos a prestações em sentido estritu (direitos a prestações sociais materiais), vinculados prioritariamente às funções do Estado Social.

Com efeito, sintetizando, os direitos de defesa como já mencionado, asseguram as liberdades, os direitos prestacionais buscam favorecer as condições materiais indispensáveis ao desfrute efetivo dessas liberdades. Não há, entretanto, somente direitos a uma prestação fática, também se incluem na função de direitos fundamentais, prestações jurídicas. Existem direitos fundamentais cujo objeto se esgota em uma prestação de natureza normativa. $\mathrm{O}$ fim do direito será a normatização pelo Estado do bem jurídico protegido como direito fundamental. Isso ocorre, por exemplo, quando a Constituição, em certas hipóteses, estabelece, diretamente, a obrigação de o Estado editar normas penais para coibir práticas 
atentatórias aos direitos e liberdades fundamentais (art. 5, XLI), bem assim práticas de racismo (art. $5^{\circ}$, XLII), de tortura e de terrorismo (art. $5^{\circ}$, XLIII). Assim é o direito de acesso à Justiça que não dispensa legislação que fixe a estrutura dos órgãos prestadores desse serviço, bem assim que estabeleça normas processuais que viabilizem o pedido de solução de conflitos pelo Estado. Também, a liberdade de exercício profissional pressupõe uma disciplina da matéria no ordenamento jurídico, e assim por diante.

Para que os indivíduos possam gozar desses direitos fundamentais, o Estado deve atuar normativamente.

\section{Direitos fundamentais sociais}

Feita essa classificação, temos agora mais elementos para fixar com bastante técnica quais são os direitos sociais. Uma simples leitura da Constituição é capaz de dar-nos uma noção do que se esta por definir. Os direitos fundamentais sociais, assim como os direitos prestacionais, estão longe de denotar homogeneidade. É que sob o manto da expressão "direitos sociais" o Constituinte instituiu direitos das mais variadas naturezas. Uma coisa, contudo, é assente, a denominação não é outra senão "direitos sociais".

Primeiramente, pode assim parecer, mas não se pode compreender tais direitos como unicamente, direitos a prestações estatais, mesmo que haja ainda quem os enquadre nesta concepção, de ser o poder de reclamar do Estado certas prestações. Isto porque, como ressaltamos acima, os direitos a prestações, tomados em sentido amplo, não se restringem a direitos a prestações materiais, de tal sorte que nem todos os direitos a prestações são direitos sociais.

Por outro lado, também os direitos sociais não se limitam a uma dimensão prestacional. A conceituação correta de direitos sociais não é como direitos a prestações estatais já que nem todos os direitos prestacionais são sociais. Basta, neste sentido, apontar para os diversos exemplos que podem ser encontrados apenas no âmbito dos assim denominados "direitos dos trabalhadores", localizados nos arts. $7^{\circ}$ a 11 da nossa Constituição.

Nesse sentido então, são esclarecedoras as considerações de Ingo Sarlet (2001): 
(...) à vista do exposto, percebe-

se, com

facilidade, que

vários destes

direitos

fundamentais

sociais não

exercem a função

precípua de

direitos

a

prestações,

podendo ser, na

verdade,

reconduzidos ao

grupo dos direitos

de defesa, como

ocorre com $\mathrm{o}$

direito de greve

(art. $9^{\circ}$, da $\left.\mathrm{CF}\right)$, a

liberdade de

associação

sindical (art. $8^{\circ}$,

da $\mathrm{CF})$, e as

proibições contra

discriminações

nas relações

trabalhistas

consagradas no

art. $7^{\circ}, \quad$ incs.

XXXI e XXXII,

de nossa Lei

Fundamental.

Nem por isso

deixam segundo o ensinamento de

ilustre

constitucionalista

citado, de serem

direitos sociais.

Posto isso, nessa linha de pensamento não é a natureza prestacional que define o que se entende por direito social. Ainda nos esclarece o insigne jurista que na classificação de um direito fundamental como social há de se considerar seu retrospecto:

Eles são resultados de uma evolução que radica na já referida

Constituição

Francesa de 1793

e que passa pela assim denominada "questão social" do século XIX, passando esses direitos a ser entendidos como uma dimensão específica (segunda dimensão) dos direitos fundamentais, na medida em que 
pretendem

fornecer os

recursos fáticos

para uma efetiva

fruição das

liberdades, de tal

sorte que têm por

objetivo (na

condição de

direitos

prestacionais) a

garantia de uma

igualdade e

liberdade real,

que apenas pode

ser alcançada pela

compensação das

desigualdades

sociais.

Logo, o que se quer

salientar com isso é que deve a classificação desses direitos se destoar do panorama das liberdades públicas de dimensão própria e decorrentes de outra sigla histórica.

Como dito os direitos prestacionais não se restringem aos direitos a prestações materiais, logo direitos sociais, não devem ser conceituados como direitos a prestação. Além disso, esses direitos não se limitam ao âmbito prestacional (direitos prestacionais em sentido estritu), mas abrangem também direitos de defesa chamados de "liberdades sociais", como por exemplo, art. 199 da CB (assistência a saúde é livre (...)), art. 201, parágrafo $5^{\circ}, 206$, I,II,IV.

Destarte há na verdade duas categorias de direitos sociais: direitos sociais prestacionais e direitos sociais de defesa. Podemos inferir, portanto, que a definição de um direito social utilizando a doutrina de Jorge Miranda (apud Sarlet) - é efetuada ao considerar o ser humano em "situação concreta na ordem comunitária (social)". Assim, toda vez que lhe for conferido uma posição jurídica que o considere como membro de uma sociedade estaremos diante de um direito social cujo objetivo é precipuamente a criação e garantia de igualdade e liberdade material seja pela forma de prestação materiais ou por meio de prestações normativas, seja na manutenção do equilíbrio das relações trabalhistas. Segundo então Jorge Miranda (apud Ingo Sarlet) esses direitos sociais "são direitos à libertação social da opressão e da necessidade".

Ademais, vale ressaltar que os direitos sociais não se limitam aos expressamente positivados no Tit.II da Constituição Federal. Podem estar, à luz 
do disposto no art. $5^{\circ}, \S 2^{\circ}$, da nossa Constituição, implícitos e decorrentes do regime e dos princípios por ela adotados, havendo também, direitos sociais positivados em tratados internacionais e ainda, principalmente, localizados em outras partes do texto constitucional, especialmente na "Ordem Social".

\section{Referências bibliográficas:}

BRASIL. Constituição

(1988).Constituição da República

Federativa do Brasil. Brasília, DF: 1988.

CAMARGO, Marcelo Novelino. Direito Constitucional Para Concursos. $4^{\circ}$ ed. Forense, 2007.

GOMES, Luiz Flavio, VIGO, Rodolfo L. Do Estado de Direito Constitucional e Transnacional: Riscos e Precauções. $1^{\circ}$ ed. São Paulo. Premier, 2008.
LENZA, Pedro. Direito Constitucional Esquematizado. $12^{\circ}$ ed. São Paulo: Saraiva, 2013.

NADER, Paulo. Introdução ao Estudo do Direito. $26^{\circ} \mathrm{ed}$. Rio de Janeiro: Forense. 2006.

MAULAZ, Ralfh B. Os paradigmas do Estado de Direito - O estado Liberal, o Estado Social (Socialista) e o Estado Democrático de Direito: artigo.

SARLET, Ingo Wolfgang. Os Direitos Fundamentais Sociais Na Constituição de 1988. Revista Diálogo Jurídico, Salvador, CAJ - Centro de Atualização Jurídica, v. 1, nº. 1, 2001. Teoria dos Direitos

Fundamentais: artigo. Disponível em www.plinioleite.com.br/direito. 